\title{
Power Point Therapy: An Effective and Simple Treatment for Subacute Back Pain - A Randomized Controlled Trial
}

\author{
Michael Ofnere, ${ }^{\mathrm{a} b}$ Martin Liebhauser ${ }^{\mathrm{b}}$ Harald Walach ${ }^{\mathrm{c}-\mathrm{e}}$

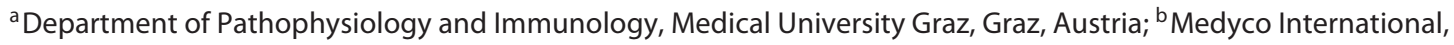 \\ Dubai, United Arab Emirates; ' ${ }^{\mathrm{C}}$ Department of Pediatric Gastroenterology, Medical University Poznan, Poznan, \\ Poland; ${ }^{\mathrm{d} D e p a r t m e n t}$ of Psychology, University Witten-Herdecke, Witten, Germany; ${ }^{\mathrm{e} C h a n g e ~ H e a l t h ~ S c i e n c e ~}$ \\ Institute, Berlin, Germany
}

\section{Keywords}

Subacute low back pain · Physiotherapy · Reflexology ·

Acupressure $\cdot$ Noninvasive treatment

\begin{abstract}
Objective: Subacute low back pain is a frequent problem with the danger of chronification. Conventional treatment options are not always effective. Power Point therapy (PPT) is a novel approach that uses reflexological insights and can be easily applied by practitioners and patients. Methods: Randomized, active controlled study comparing 10 units of PPT of 10 min each, with 10 units of standard physiotherapy of $30 \mathrm{~min}$ each. Outcomes were functional scores (Roland Morris Disability, Oswestry, McGill Pain Questionnaire, Linton-Halldén - primary outcome) and health-related quality of life (SF-36), as well as blinded assessments by clinicians (secondary outcome). Results: Eighty patients consented and were randomized, 41 to PPT, 39 to physiotherapy. Measurements were taken at baseline, after the first and after the last treatment (approximately 5 weeks after enrolment). Multivariate linear models of covariance showed significant effects of time and group $(p<0.001)$ and for the quality of life variables also a significant interaction of time by group $(p<0.001)$. Clinician-documented variables showed significant differences at follow-up ( $p=0.05$ to $p<0.0001)$. Discussion: Both physiotherapy and PPT improve subacute low back pain significantly. PPT is likely more effective and should be studied further.

(c) 2019 S. Karger AG, Basel
\end{abstract}

(c) 2019 S. Karger AG, Basel

\author{
Schlüsselwörter \\ Subakute Rückenschmerzen · Physiotherapie · \\ Reflexzonentherapie · Akupressur · Nicht invasiv
}

\section{Zusammenfassung}

Hintergrund: Subakute Rückenschmerzen sind häufig und werden oft chronisch. Konventionelle Behandlungen sind nicht immer erfolgreich. Power Point Therapie (PPT) ist eine neue Therapieform, die auf Einsichten der Reflexzonentherapie beruht und durch Behandler und Patienten leicht anwendbar ist. Methode: Randomisierte, klinische, pragmatische Studie, in der 10 Einheiten PPT mit je 10 Min Dauer mit 10 Einheiten leitlinienbasierter Physiotherapie mit je 30 Minuten Dauer verglichen wurden. Zielkrietieren waren die Funktion (Roland Morris Disability, Oswestry, McGill Pain, Linton-Halldén/Orebrö als Hauptkriterien) und die gesundheitsbezogene Lebensqualität (SF-36) und verblindet erfasste klinische Masse (Nebenkriterien). Ergebnisse: 80 Patienten gaben ihr Einverständnis und wurden randomisiert, 41 zu PPT, 39 zu Physiotherapie. Gemessen wurde bei Einschluss, nach der ersten und nach der letzten Behandlung (etwa 5 Wochen nach Beginn der Behandlung). Multivariate lineare Modelle mit Eingangswert als Kovariate zeigten signifikante Effekte der Zeit und der Gruppe $(p<0.001)$ und für die Lebensqualität auch eine signifikante Interaktion zwischen Zeit und Gruppe ( $p<0.001)$. Die verblindeten klinischen Ratings zeigten signifikante Unterschie- 
de zum Behandlungsende ( $p=0.05$ bis $p<0.0001$ ). Dis kussion: Sowohl Physiotherapie als auch PPT verbessern Patienten mit subakuten Rückenschmerzen deutlich. PPT ist dabei erfolgreicher und sollte weiter untersucht werden.

\section{Introduction}

Low back pain is the most common reason for patients to consult a doctor. It is the third common indication for physical therapies like massages, acupressure, osteopathic treatments, and it is the main reason for sick leave in western countries [1-3]. The prevalence of lower back pain is between 25 and $63 \%$, depending on age, type of job, socioeconomic status, country of origin, and psychological factors. Even up to $40 \%$ teenagers have back pain, and about $58 \%$ elderly people struggle with it $[1,4,5]$. Reasons and causes for back pain are diverse: strained or torn muscles and ligaments, ruptured or displaced discs, and skeletal irregularities such as hip displacements and osteoporosis are among them. While gender is not a risk factor, back pain is more likely with older age. An important protective factor is higher education. Common risk factors include: more other physical symptoms, higher job strain, carrying heavy loads, having to stand in the job, suffering vibrations, and repetitive movements, while sitting and computer work in themselves are no risk factors [4]. There is a considerable chance of acute low back pain to become chronic. In a recent cohort study of 605 acute back pain patients, $32 \%$ reported themselves fully recovered after 6 months, and 9\% reported a worsening of the problems or felt the same [6]. About $10 \%$ of the patients with back pain proceed with surgical operation to treat the pain [7]. The annual direct costs for patients with chronic back pain are around EUR 3,100 per patient, and the indirect costs are around EUR 17,600, which makes chronic back pain one of the main burdens for the health care system $[8,9]$, and consequently preventing chronification a prime target. Every effective pain treatment, treating the cause of the pain, would be a massive benefit for patients, an important medical progress, and a valuable support for the healthcare system. A noninvasive treatment, which could be used for self-care, would be even more valuable and would result in further effectiveness, time, and cost savings.

Power Point therapy (PPT) is such a conservative treatment system. It is mainly applied for various musculoskeletal pain syndromes and related issues. PPT is based on the theories of classic acupuncture, neuromuscular reflexology, and systems theoretical approaches like biocybernetics [10-13]. It has been developed after four decades of experience by Mr. Gerhard Egger, an Austrian therapist, who developed this therapy into a system. Hun- dreds of massage and physiotherapists in Europe were trained to use it, and apply it currently in their practice. The treatment can be easily learned. It is taught by professional PPT therapists to students and patients for selfapplication in weekend courses, followed by advanced courses for specialists.

The core hypothesis of the PPT system is that various pain syndromes, including lower back pain, have its origin, among others, in a functional pelvic obliquity. This in turn leads to a static imbalance in the posture of the body. This may result in mechanical strain and possible spinal nerve irritation that may radiate and thus affect dermatomes, myotomes, enterotomes, sclerotomes, and neurotomes of one or more vertebra segments. Therefore, treating reflex zones for the pelvis would reduce and possibly resolve the functional obliquity, improve the statics, and thus cure the pain through improved function, according to this theoretical model $[14,15]$. In addition, reflex therapy might be beneficial also in patients with unknown causes of back pain.

This rationale is supported by outcomes of studies in reflexology:

Some authors reported that classic reflexology had effects on hemodynamic processes in human and that acupressure reduced pain in back pain patients [3, 16-18]. More recent reviews suggest that reflexology should be integrated into guidelines for treating back pain, and it should be used in clinical routine because of its positive effects $[18,19]$. Usually such therapies are not broadly used in clinical routine, but in contrast, physiotherapy and analgesics are considered to be the gold standard for conservative treatment of lower back pain despite conflicting evidence [20]. Surprisingly, no effect was observed when physiotherapy was compared with a sham neck massage, a walking program, or balneological treatments for lower back pain in single studies [21-23]. In contrast, acupuncture, yoga, and spinal manipulation showed significant effects for treating back pain $[9,24$, 25 ]. Evidence from systematic reviews shows that spinal manipulation has small effects short term, but unclear effects long term $[26,27]$. Pharmacotherapies are only evaluated for short-term use up to 3 months and have medium (opiates) to small effects (nonsteroidal anti-inflammatory drugs [NSAIDs], SSRIs, tricyclic antidepressants) vis-à-vis placebo, and long-term use is neither well researched nor recommended [28]. Exercise therapy and physiotherapy have medium range effects against waitlist and treatment as usual, but it is unclear how good the evidence really is [29].

Various international guidelines suggest conservative treatments as first-line treatments and deemphasize pharmacological treatments as first-line intervention [30-33]. Only in the case of compressed nerves with clinical symptoms and/or positive findings in magnetic reso- 
Fig. 1.PPT stimulation areas and treatment points.
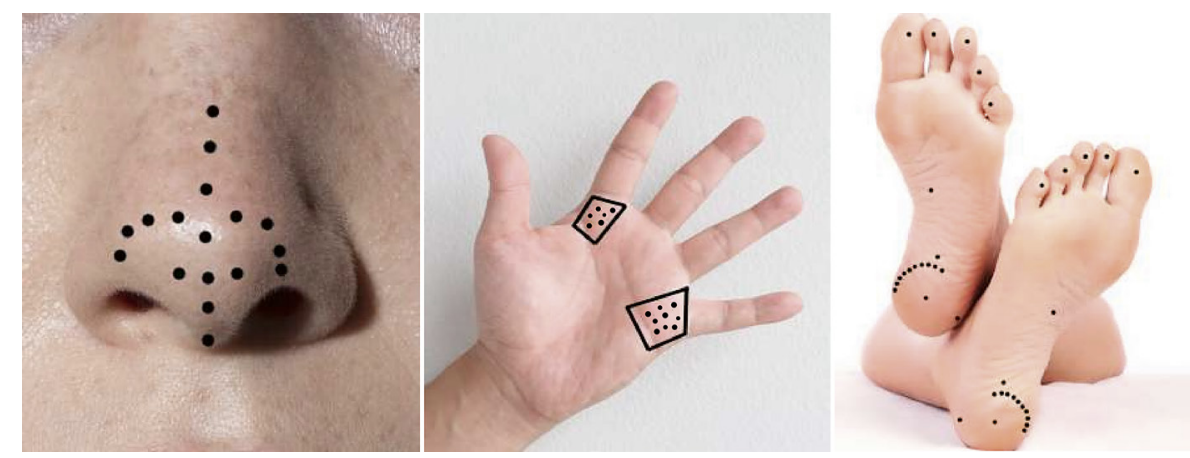

nance imaging is a surgical decompression suggested. In any case, back pain reduces quality of life considerably, and decreases the level of activities.

Effective therapies, potentially for the cause of the symptoms, would help patients and could reduce the massive annual expenses that are paid for treatments of lower back pain. This situation prompted us to study PPT therapy as a potentially effective, noninvasive, and costsaving procedure that is amenable to self-care, and, theoretically, addresses some causally underlying problems. PPT uses blunt needle tips to apply pressure to specific reflex points on the nose, hand, and feet. PPT has been used for more than 10 years in treating patients with musculoskeletal problems, especially lower back pain. Subjectively, most of the reports were positive, often even after a single treatment, and in most cases after the usual series of 10 treatments of 10 min each. Therefore, the goal of this study was to evaluate objectively the effectiveness of PPT in comparison with conventional physiotherapy, as it is suggested by the guidelines for conservative treatment of lower back pain. Thus, our study question was: Is it possible to reduce back pain and improve motor function of the back through pressing pelvis related reflex zones on the feet, the hand, and the nose?

\section{Methods}

This study was designed as a randomized, controlled, partly observer-blinded, monocentric study running in Austria between 2015 and 2016.

\section{Intervention}

Power Point Therapy

The therapy introduced in this study, PPT, is based on reflexology. It assumes that various body parts are reflexively connected via segmental-neural interactions and distant innervations [34]. Thereby, pain sensations might be experienced distally to the anatomical cause of the pain, for instance as a nerve irritation. But this can also be a way of treatment. Thus, the treatment has the goal to produce a regulating effect on the pelvis and its stabilizing muscles to fix a possible functional pelvis obliquity and the pain resulting from it. First, the therapy system uses a cream that is applied only on scars, with the aim of increasing perfusion in this area. This is, because scars might act as neuromuscular interference factors caused by their tissue due to subchronic inflammation. Second, a small metal stick about $15 \mathrm{~cm}$ in length with a blunt tip like a felt-tip pen (therapy stick) is used to apply pressure for a couple of seconds on different reflex points/areas of the pelvis which can be found on the nose, hands, and feet (Fig. 1).

The total treatment takes about $10 \mathrm{~min}$. In general, this procedure can be, and often is, applied by patients themselves, but in this trial it was performed by a professional PPT therapist. No side effects, except local pain where pressure is applied, have been reported so far. Thus, this study aims at objectifying and evaluating the effects of the therapy, but not to investigate the involved mechanisms, which will be part of future studies.

\section{Control}

The control group underwent a standard physiotherapy protocol, which is recommended for treatment of lower back pain by the Austrian School of Physiotherapy, Krems. This protocol contains 10 units at $30 \mathrm{~min}$ with active and passive treatment elements. The active ones are mobilization of the spine to increase the range of motion, strengthening for static stabilization of the core and various coordination and muscle training exercises, whereas the passive ones are applications of thermal pads, massages including lymph drainage, electromyostimulation, and application of the same cream as in the PPT group.

The goal of treatment in the control group was not just to reduce pain, but also to evaluate and treat the causes of pain, and prevent chronification. Thus, the control treatment is considered to be optimal from the point of view of current guidelines [35]. Therefore, specific treatments were chosen individually from the potential range of passive and active treatments, for each patient's needs, similar to real-world clinical conditions. The control group treatment was performed by a professional certified physiotherapist different from the PPT therapist, in order to generate a fair evaluation.

In addition to these physical treatments, patients of both groups were allowed to treat peaks of pain autonomously with NSAIDs, should the need arise, but were asked to use these treatments sparingly, as well as to avoid them $12 \mathrm{~h}$ before and after each physical treatment due to possible examination bias.

\section{Trial Flow}

Patients were informed by print media about the opportunity to participate in the study. Interested persons were informed about the details of the study at the International Academy of PPT by a physician specialized in sports medicine. The flow diagram is represented in Figure 2.

The following criteria were assessed: 
Fig. 2. Trial flow chart of the study including randomization procedure and time in-

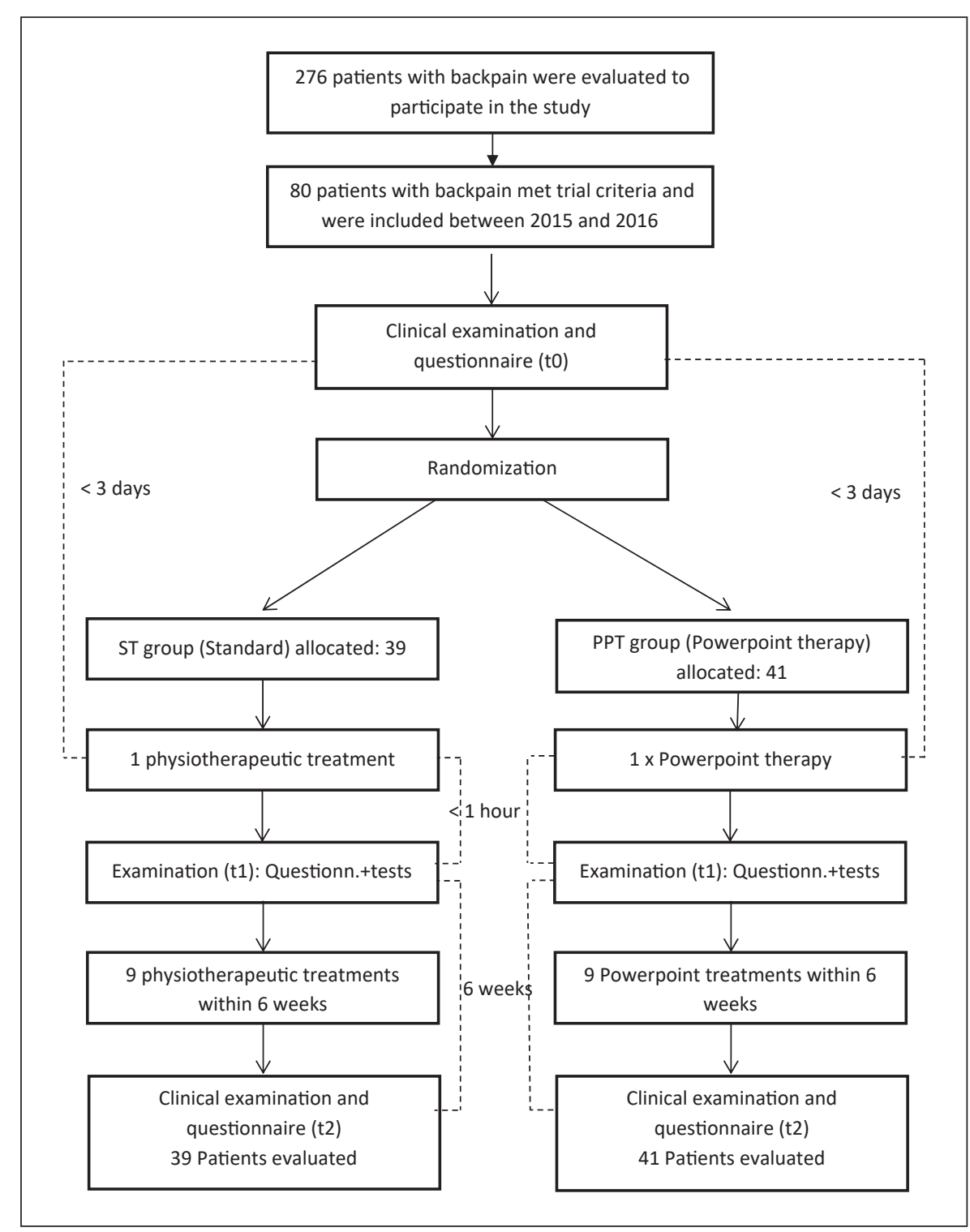
tervals.

Inclusion Criteria

The study participants had to have subacute back pain, lasting less than 3 months, and actual pain level of VAS $\geq 5$ out of 10 . Patients had to be between 20 and 70 years, their body mass index had to be between 18 and 35 .

\section{Exclusion Criteria}

Patients were excluded from the study if they had had any surgical procedures at the spine at any previous time. Any acute surgical indication also meant exclusion from the study. The patients were not to use pain killers (NSAIDs, opiates) on a regular basis. Moreover, any permanent drug treatment was an exclusion criterion.

Diagnostic Procedure and Measurements

If all inclusion and none of the exclusion criteria were fulfilled, patients were invited to participate in the study. After giving written informed consent at inclusion ( $\mathrm{t} 0$, baseline), each patient completed a 125-item questionnaire including sociodemographic variables (sex, age, height, weight, education, smoking behavior), compliance evaluation (trust, relationship, satisfaction), medications, therapy expectations (measured on a numerical rating scale between 0-10), the Roland-Morris Disability Questionnaire (range: 0-24) [36], the Oswestry Low Back Pain Disability Index (0-100\% disability) [37], The Short-Form 36 questionnaire (0-100\% functioning) [38], the Visual Analogue Scale in four positions (moving, standing, sitting, lying down), the Short-Form McGill Pain Questionnaire (range: 0-45) [39], and the Linton-Halldén (Orebro Screening) score (range 0-200; scores above 105 indicate patient at risk) $[40,41]$. All validated instruments were used in their current appropriate German version.

The following clinical examinations were performed:

The spine was inspected visually, and pictures were taken. The level of the spina iliaca superior posterior was compared on the left and the right side by using a spirit level and a measure tape, with $5 \mathrm{~mm}$ difference between the left and the right side considered asymmetric. The distance between fingers and floor when bending forward with straight knees was measured with a measure tape. The presence of pain after pressure on the symphysis was assessed, and finally the Long-Sit test and Faber test were applied [42, 43]. In addition, the presence of a Trendelenburg sign, and individual comments were noted. These diagnostic procedures were repeated 
Table 1. Demographics of the study sample: mean values of continuous variables (standard deviation) [median] at baseline

\begin{tabular}{lccc}
\hline Variable & $\begin{array}{l}\text { Power Point } \\
(n=41)\end{array}$ & $\begin{array}{l}\text { Physiotherapy } \\
(n=39)\end{array}$ & $\begin{array}{l}\text { Total } \\
(n=80)\end{array}$ \\
\hline Age, years & $44.5(15.0)$ & $44.4(12.3)$ & $44.4(13.7)[45]$ \\
Height, cm & $174.8(9.3)$ & $174.1(8.1)$ & $174.5(8.7)[175]$ \\
Weight, kg & $76.6(12.1)$ & $74.7(14.4)$ & $75.7(13.3)[77.5]$ \\
BMI & $25.1(3.8)$ & $24.5(3.7)$ & $24.8(3.7)[24.9]$ \\
Expectation $(0-10)$ & $8.5(2.1)$ & $8.2(1.9)$ & $8.4(2.0)[9.5]$ \\
\hline
\end{tabular}

after the first treatment (t1) of each patient and after the 10th (final) treatment ( $\mathrm{t} 2$ ) after about 5-6 weeks.

Both the testing procedures and the filling in of the questionnaires were performed on site and took about 15 min each.

\section{Outcome Variables and Blinding}

The primary outcome variables were the international functional scores (Roland-Morris, Oswestry, Linton-Halldén, McGill) that have been used to evaluate pain, social and life-quality conditions (SF-36) to compare the score results of $\mathrm{t} 0$ to $\mathrm{t} 1$ and $\mathrm{t} 2$, respectively.

As secondary variables, the clinical parameters assessed blindly by the clinician were used.

After the baseline assessment was completed, patients were randomized into two treatment groups by using an online tool based on a random algorithm that creates random numbers sequentially (www.randomizer.org). The study secretary informed the patients about the treatment group and told them their individual ID. Additionally, they were instructed not to disclose their treatment group to avoid any unblinding. Thus, allocation blinding was achieved, and doctors and patients were unable to tell which group the next patient would be allocated to.

Patients received the first treatment within 3 days after inclusion; patients in group PPT received 10 units of PPT as described above. Patients in group ST received 10 units of standard physiotherapy therapy as described above. Within $1 \mathrm{~h}$ after the first treatment, each patient was reevaluated with clinical tests and questionnaires as described above ( $\mathrm{t} 1$ - after 1st treatment). After the 10th treatment, usually about 5 weeks after the initial one, each patient performed all clinical tests and the questionnaire again ( 2 - end of treatment).

When filling in the questionnaires, patients were left to themselves, and the physician conducting the clinical tests was blind to the assigned conditions of the patients. Thus, the study can be considered observer-blind regarding the clinical outcomes. Blinding for the self-report questionnaires was obviously impossible, but patients were given the information that both treatments would be effective; so, they had no incentive to bias their answers.

\section{Statistical Methods and Analysis}

When this study was performed, PPT had never been evaluated before. Because of the high success rates in anecdotal reports after this therapy, and assuming a clinically large between-group effect size, we deemed 40 patients per group sufficient to determine the effects of the therapy for this study. With such a sample size, a large clinical effect above $d=0.7$ can be detected with reasonable statistical power of at least $80 \%$ or higher and a two-sided test at alpha $=0.05$.

Data preparation was performed using Microsoft Excel. For data analysis, Statistica version 8 was used. Kolmogoroff-Smirnov tests and graphical analyses were used for evaluation of normal distribution. Continuous data were analyzed by multivariate linear models using baseline scores as covariates and a time factor (posttreatment, follow-up), and interaction terms were appropriate, time trends in rank order data were analyzed using nonparametric Friedman analysis. For the categorical data, differences between the two groups were analyzed using Fisher's exact test, and Pearson's $\chi^{2}$ test with Yates' correction for small cell frequencies. The level of significance was set at $p \leq 0.05$. Analysis was performed as intention to treat.

The data were submitted as a fully prepared XLS file with group coding presented as 1 and 2 . Hence, the statistical evaluation was fully blinded. In a first step, the demographical description of the sample was produced. For the evaluation of the clinical effect, the target variables were reordered into a repeated measurement format. The potential importance of covariates was tested using correlational analysis. Where appropriate and where variables correlated with outcomes, covariates were included, and the baseline measurement value was used as a covariate as default. Since all outcome variables conformed well to preconditions of normality and homogeneity of variance and were continually scaled, linear models were applied. Summary variables were used before any single variable effect was tested. Since there were no patients lost to follow-up, no missing data treatment procedures had to be applied.

This was the first study of PPT, and it was unknown which measures would be most sensitive. Hence, all patient-documented functional outcome measures were defined as primary outcomes in the protocol and investigated simultaneously as a 5-dimensional outcome parameter. Thus, the analysis followed a logic of minimizing capitalization of chance by using general linear models that corrected for potential baseline differences and the influence of the correlation of outcomes with baseline values. The analysis estimated effects simultaneously for groups of variables in linear models (i.e., simultaneously the primary functional outcomes together - Roland Morris Disability, Oswestry, McGill, Linton-Halldén; the quality of life scores together - SF-36 scales; and the continuous clinician-rated outcomes).

\section{Results}

\section{Description of the Study Sample}

Altogether, 80 patients were included and randomized into two groups (Fig. 2), 41 into the PPT group, and 39 into the physiotherapy group. The results are presented in Tables 1 and 2 for continuous and dichotomous or categorical outcomes.

As can be seen from the data, none of these differences was extreme, testifying to a good success in evenly distributing patients across groups. Significance tests for base- 
Table 2. Demographics of the study sample: frequency (\%) of categorical variables at baseline

\begin{tabular}{|c|c|c|c|}
\hline Variable & $\begin{array}{l}\text { Power Point } \\
(n=41)\end{array}$ & $\begin{array}{l}\text { Physiotherapy } \\
(n=39)\end{array}$ & $\begin{array}{l}\text { Total } \\
(n=80)\end{array}$ \\
\hline Female sex & $20(48.8 \%)$ & $19(48.7 \%)$ & $39(50.0 \%)$ \\
\hline \multicolumn{4}{|l|}{ Schooling } \\
\hline Level 2 & $21(51.2 \%)$ & $19(48.7 \%)$ & $40(50.0 \%)$ \\
\hline Level 3 & $7(17.1 \%)$ & $7(18.0 \%)$ & $14(17.5 \%)$ \\
\hline Level 4 & $6(14.6 \%)$ & $8(20.5 \%)$ & $14(17.5 \%)$ \\
\hline Level 5 & $7(17.1 \%)$ & $5(12.8 \%)$ & $1215.0 \%)$ \\
\hline Smoking, yes & $10(24.4 \%)$ & $9(23.1 \%)$ & $19(23.7 \%)$ \\
\hline \multicolumn{4}{|l|}{ Pack years } \\
\hline 0 & $31(83.8 \%)$ & $30(83.3 \%)$ & $61(83.6 \%)$ \\
\hline 1 & $0(0.0 \%)$ & $2(5.6 \%)$ & $2(2.7 \%)$ \\
\hline 3 & $0(0.0 \%)$ & $1(2.8 \%)$ & $1(1.4 \%)$ \\
\hline 5 & $1(2.7 \%)$ & $0(0.0 \%)$ & $1(1.4 \%)$ \\
\hline 9 & $1(2.7 \%)$ & $0(0.0 \%)$ & $1(1.4 \%)$ \\
\hline 10 & $1(2.7 \%)$ & $0(0.0 \%)$ & $1(1.4 \%)$ \\
\hline 15 & $0(0.0 \%)$ & $1(2.7 \%)$ & $1(1.4 \%)$ \\
\hline 16 & $0(0.0 \%)$ & $1(2.7 \%)$ & $1(1.4 \%)$ \\
\hline 20 & $1(2.7 \%)$ & $2(2.7 \%)$ & $2(2.7 \%)$ \\
\hline 25 & $1(2.7 \%)$ & $0(0.0 \%)$ & $1(1.4 \%)$ \\
\hline 80 & $1(2.7 \%)$ & $0(0.0 \%)$ & $1(1.4 \%)$ \\
\hline \multicolumn{4}{|l|}{ Form of the spine } \\
\hline S shape & $24(30 \%)$ & $8(10 \%)$ & $32(40 \%)$ \\
\hline Stretched & $2(2.5 \%)$ & $7(8.7 \%)$ & $9(11.2 \%)$ \\
\hline Kyphosis left & $7(8.7 \%)$ & $7(8.7 \%)$ & $14(17.5 \%)$ \\
\hline Hyperlordosis & $2(2.5 \%)$ & $9(11.2 \%)$ & $11(13.7 \%)$ \\
\hline Kyphosis right & $6(7.5 \%)$ & $8(10 \%)$ & $14(17.5 \%)$ \\
\hline \multicolumn{4}{|l|}{ Height of spina illiaca superior } \\
\hline Equal & $3(3.7 \%)$ & $10(12.5 \%)$ & $13(16.5 \%)$ \\
\hline Left higher & $14(17.5 \%)$ & $7(8.7 \%)$ & $21(26.2 \%)$ \\
\hline Right higher & $24(30 \%)$ & $22(27.5 \%)$ & $46(57.5 \%)$ \\
\hline \multicolumn{4}{|l|}{ Pain } \\
\hline At rest & $6(7.5 \%)$ & $8(10 \%)$ & $14(17.5 \%)$ \\
\hline When moving & $6(7.5 \%)$ & $6(7.5 \%)$ & $12(15 \%)$ \\
\hline On Pressure & $1(1.25 \%)$ & $0(0 \%)$ & $1(1.25 \%)$ \\
\hline Multiple & $25(31.2 \%)$ & $24(30 \%)$ & $49(61.2 \%)$ \\
\hline Symphysis painful & $41(51 \%)$ & $32(40 \%)$ & $73(91.2 \%)$ \\
\hline \multicolumn{4}{|l|}{ Medial malleolus symmetry } \\
\hline Symmetric & $1(1.25 \%)$ & $6(7.5 \%)$ & $7(8.7 \%)$ \\
\hline Asymm. left & $16(20 \%)$ & $17(21.2 \%)$ & $33(41.2 \%)$ \\
\hline Asymm. right & $24(30 \%)$ & $16(20 \%)$ & $40(50 \%)$ \\
\hline Faber test positive & $25(31.2 \%)$ & $27(33.7 \%)$ & $52(65 \%)$ \\
\hline Trendelenburg sign positive & $5(6.2 \%)$ & $1(1.2 \%)$ & $6(7.5 \%)$ \\
\hline
\end{tabular}

Schooling levels: level 1 = no school certificate, level 2 = general school, level 3 = GCSE, level 4 = A-level/high school, level 5 = university degree.

line demographics are actually discouraged by guidelines, since randomization and balancing of variables are theoretical concepts [44-46]. Also, all outcome variables were normally distributed (visual inspection), and evenly distributed across groups. The Linton-Halldén score is higher in the PPT group. Baseline data are given in Table 3.
By looking at the data of the outcome measure at baseline, one can see that the group is actually quite seriously suffering, as most SF-36 scales are below the 50\% range and the pain measures are high. 
Table 3. Outcome variables at baseline

\begin{tabular}{|c|c|c|c|}
\hline Variable & $\begin{array}{l}\text { Power Point } \\
(n=41)\end{array}$ & $\begin{array}{l}\text { Physiotherapy } \\
(n=39)\end{array}$ & $\begin{array}{l}\text { Total } \\
(n=80)\end{array}$ \\
\hline Roland-Morris Disability & $8.83(3.9)$ & $8.69(4.5)$ & $8.76(4.2)[8.0]$ \\
\hline Oswestry Low Back Pain & $16.74(3.6)$ & $18.05(5.8)$ & $17.37(4.8)[16.0]$ \\
\hline SF-36 Total & $49.05(13.3)$ & $49.88(15.2)$ & $49.45(14.2)[49.7]$ \\
\hline SF-36 Physical Function & $63.41(15.1)$ & $65.92(21.2)$ & $64.64(18.2)[65.0]$ \\
\hline SF-36 Role F. Physical & $31.10(37.0)$ & $30.13(37.7)$ & $30.62(37.1)[0]$ \\
\hline SF-36 Role F. Emotional & $52.84(46.5)$ & $49.57(48.9)$ & $51.25(47.4)[66.7]$ \\
\hline SF-36 Energy & $49.63(14.0$ & $47.95(15.9)$ & $48.81(14.9)[45.0]$ \\
\hline SF-36 Emotional Funct. & $42.27(14.5)$ & $41.23(14.8)$ & $41.76(14.6)[42.0]$ \\
\hline SF-36 Social Function & $61.28(25.0)$ & $65.06(23.0)$ & $63.12(23.9)[62.5]$ \\
\hline SF-36 Pain & $33.78(16.6)$ & $38.53(17.7)$ & $36.09(17.2)[35.0]$ \\
\hline SF-36 General Health & $58.05(9.1)$ & $60.78(12.4)$ & $59.33(10.8)[60.0]$ \\
\hline McGill Pain Sensory & $9.90(5.6)$ & $9.97(5.9)$ & $9.94(5.7)[9.0]$ \\
\hline McGill Pain Affective & $2.93(2.5)$ & $2.46(1.9)$ & $2.70(2.2)[2.0]$ \\
\hline McGill Pain Total & $12.83(7.7)$ & $12.44(7.2)$ & $12.64(7.4)[11.5]$ \\
\hline Linton-Halldén & $92.12(19.5)$ & $88.49(24.8)$ [80.44-96.53] & $90.35(22.2)[89.0]$ \\
\hline Pain when moving (100 mm VAS) & $46.8(24.4)$ & $42.5(21.7)$ & $44.7(23.1)[50]$ \\
\hline Pain standing (100 mm VAS) & $54.6(22.0)$ & $50.8(22.4)$ & $52.7(22.2)[58.5]$ \\
\hline Pain sitting (100 mm VAS) & $58.5(23.9)$ & $51.9(23.1)$ & $55.2(23.6)[60]$ \\
\hline Pain lying (100 mm VAS) & $49.9(26.3)$ & $51.3(28.5)$ & $50.6(27.2)[58]$ \\
\hline Pain (average) (100 mm VAS) & $52.5(19.3)$ & $49.1(18.4)$ & $68.4(17.7)[52.5]$ \\
\hline Number of medications & $1(0.9)$ & $0.64(0.9)$ & $0.82(0.92)[1]$ \\
\hline Side difference spina iliaca, $\mathrm{cm}$ & $0.96(0.42)$ & $0.77(0.58)$ & $0.87(0.51)[1]$ \\
\hline Finger-floor distance, $\mathrm{cm}$ & $16.36(14.9)$ & $15.90(13.9)$ & $16.14(14.4)[15]$ \\
\hline Medial malleolus asymmetry when sitting, $\mathrm{cm}$ & $1.08(0.37)$ & $0.92(0.52)$ & $1.01(0.45)[1]$ \\
\hline
\end{tabular}

Data indicate mean values (standard deviation) [95\% confidence interval; median]; upper part: patient reported outcomes at baseline; lower part: clinician-documented outcomes.

\section{Statistical Evaluation of the Experimental Design}

The results of the statistical tests are presented in $\mathrm{Ta}$ bles 4-6. The unadjusted mean scores and standard deviations together with the univariate $p$ values derived from the multivariate analyses are presented in Table 7 for all continuous variables. The results for the categorical clinician-documented outcomes are presented in Table 8.

As can be seen from Table 4 , the time by group interaction term was small (partial eta ${ }^{2}=0.097$ ) and not significant for the functional scores, but large (partial eta ${ }^{2}=$ 0.348 ) and significant for the SF-36 scores (Table 5). In both analyses, the group factor and the time factor were highly significant, documenting both a large improvement over time (partial eta ${ }^{2}=0.225$ and partial eta ${ }^{2}=$ 0.413 , respectively) and a large difference between groups ( partial eta $^{2}=0.283$ and partial eta ${ }^{2}=0.383$ ).

The analysis of the continuous variables of the secondary outcomes, clinician rated variables (Table 6), revealed a highly significant group effect (partial eta ${ }^{2}=0.37$ ), but neither a significant time, nor a significant interaction effect.

The analysis of the categorical variables of the secondary outcomes, the clinician rated outcomes, is presented in Table 8. These variables were assessed for change over
Table 4. Multivariate analysis of covariance with posttreatment (after 1st treatment) and end-of-treatment scores as repeated measurement time factor; baseline scores as predictors across primary outcomes (Roland-Morris, Oswestry, McGill Total and Linton-Halldén scores) omitted

\begin{tabular}{lcccc}
\hline Variable & $\begin{array}{l}\text { Wilk's } \\
\text { lambda }\end{array}$ & $F_{4 / 71}$ & $p$ & $\begin{array}{l}\text { Partial } \\
\text { eta }^{2}\end{array}$ \\
\hline Group & 0.717 & 7.01 & $<0.00001$ & 0.283 \\
Time & 0.775 & 5.14 & 0.001 & 0.225 \\
Time $\times$ group interaction & 0.903 & 1.91 & 0.12 & 0.097 \\
\hline
\end{tabular}

Table 5. Multivariate analysis of covariance with 1st treatment and end-of-treatment scores as repeated measurement time factor and baseline scores as predictors (all predictors significant; data omitted) across the scales of the SF-36

\begin{tabular}{lllll}
\hline Variable & $\begin{array}{l}\text { Wilk's } \\
\text { lambda }\end{array}$ & $\mathrm{F}_{8 / 63}$ & $p$ & $\begin{array}{l}\text { Partial } \\
\text { eta }^{2}\end{array}$ \\
\hline Group & 0.617 & 4.88 & 0.0001 & 0.383 \\
Time & 0.587 & 5.54 & 0.00003 & 0.413 \\
Time $\times$ group interaction & 0.652 & 4.21 & 0.0004 & 0.348 \\
\hline
\end{tabular}


Table 6. Multivariate analysis of covariance with 1st treatment and end-of-treatment scores as repeated measurement time factor and baseline scores as predictors across clinician measured outcomes (number of medications, average pain (VAS), spina iliaca asymmetry, finger-floor distance)

\begin{tabular}{llccc}
\hline Variable & Wilk's lambda & $\mathrm{F}_{4 / 71}$ & $p$ & Partial eta $^{2}$ \\
\hline Average pain (VAS) baseline & 0.620 & 10.86 & $<0.000001$ & 0.379 \\
Number of medications baseline & 0.578 & 12.90 & $<0.000001$ & 0.421 \\
Side asymmetry baseline & 0.813 & 4.06 & 0.005 & 0.186 \\
Finger-floor distance baseline & 0.396 & 27.11 & $<0.000001$ & 0.604 \\
Group & 0.629 & 10.42 & $<0.00001$ & 0.370 \\
Time & 0.959 & 0.74 & 0.5 & 0.04 \\
Time $\times$ group interaction & 0.965 & 0.63 & 0.6 & 0.03 \\
\hline
\end{tabular}

Fig. 3. Linton-Halldén score at the end of 1 st treatment and after the treatment from multivariate analysis of covariance with baseline score as covariate.

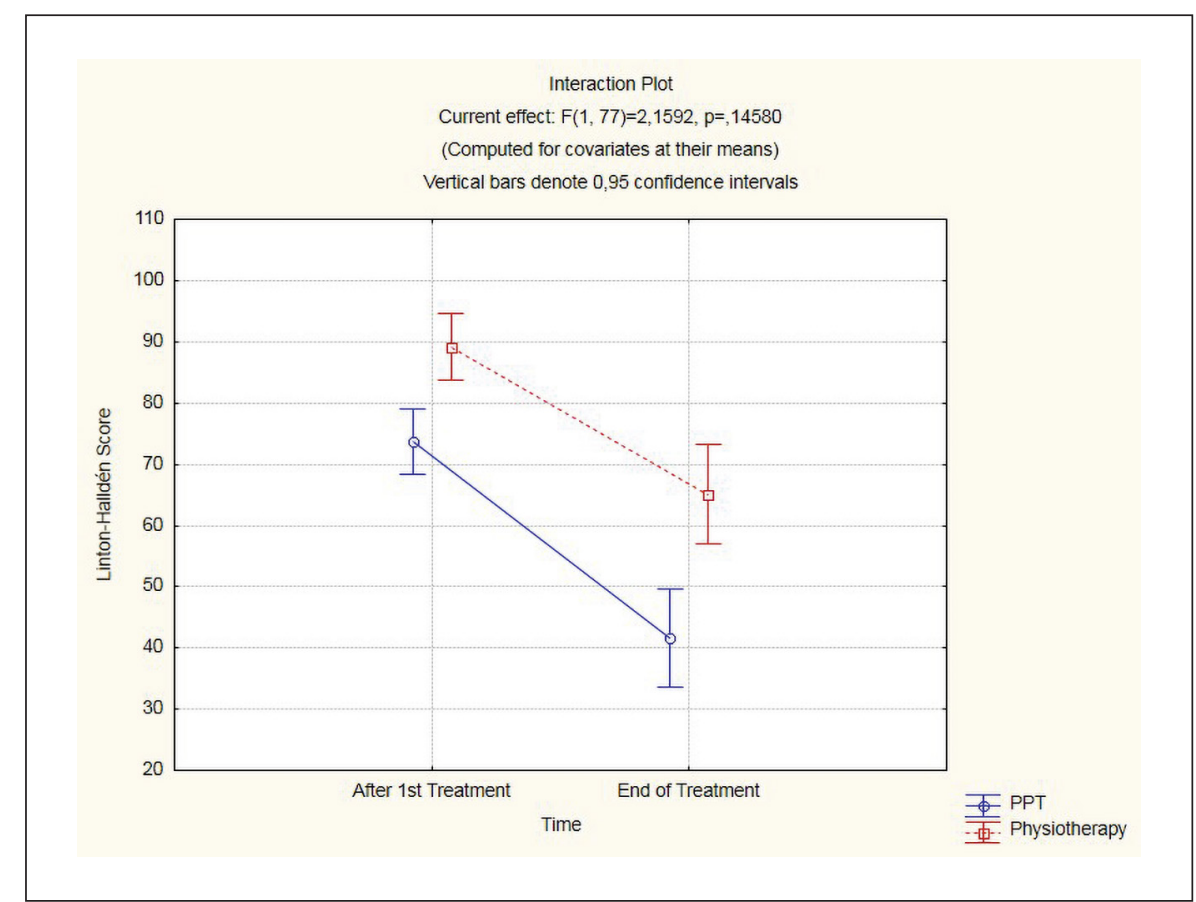

time nonparametrically (Friedman analysis), which showed highly significant changes over time $(p<0.01-$ $p<0.0001)$. Differences between groups are clearly visible at the end of the treatment series, when all variables revealed a statistically significantly better outcome for the PPT group $(p<0.05)$.

The analysis of the functional scores shows that both groups improve considerably over time in a parallel fashion, but the PPT group improves more. Figure 3 gives an example of this time development, showing the LintonHalldén Score.

The analysis of the clinician-documented outcomes demonstrates the same: both groups improve, but he PPT group improves more. For instance, only 2 patients in the PPT group had a still visible asymmetry in the malleoli and none at the spinae iliaca superior at the end of the treatment, while in the physiotherapy group 17 patients were still asymmetric in the malleoli and 14 at the spinae iliaca superior. Pain was completely gone in 31 of the 41 PPT patients, and in 13 out of 39 physiotherapy patients (Table 8).

Pain medication was used in the placebo group by 4 patients: 2 patients took $500 \mathrm{mg}$ ibuprofen two times on 1 day each; 1 patient took diclofenac three times on 3 different days, and 1 patient applied diclofenac pain gel two times on the back. In the PPT group, 1 patient took 100 mg diclofenac one on 1 day.

\section{Discussion}

\section{Summary of Findings}

This was the first randomized controlled trial of PPT, a novel treatment for pain using reflex points on the feet, 
Table 7. Results of treatment in outcome variables over time and univariate levels of significance resulting from multivariate analyses of covariance (Tables 4-6)

\begin{tabular}{|c|c|c|c|c|c|c|}
\hline \multirow[t]{2}{*}{ Variable } & \multicolumn{2}{|c|}{ After 1st treatment } & \multirow[t]{2}{*}{$p$} & \multicolumn{2}{|c|}{ End of treatment } & \multirow[t]{2}{*}{$p$} \\
\hline & $\begin{array}{l}\text { Power Point } \\
(n=41)\end{array}$ & $\begin{array}{l}\text { physiotherapy } \\
(n=39)\end{array}$ & & $\begin{array}{l}\text { Power Point } \\
(n=41)\end{array}$ & $\begin{array}{l}\text { physiotherapy } \\
(n=39)\end{array}$ & \\
\hline Roland-Morris Disability & $\begin{array}{l}6.56(3.8) \\
{[5.37-7.75]}\end{array}$ & $\begin{array}{l}7.54(4.3) \\
{[6.13-8.95]}\end{array}$ & 0.04 & $\begin{array}{l}2.05(3.3) \\
{[1.01-3.09]}\end{array}$ & $\begin{array}{l}3.23(3.7) \\
{[2.02-4.43]}\end{array}$ & 0.04 \\
\hline Oswestry & $\begin{array}{l}14.46(3.7) \\
{[13.27-15.65]}\end{array}$ & $\begin{array}{l}16.95(5.0) \\
{[15.32-18.58]}\end{array}$ & 0.01 & $\begin{array}{l}11.15(2.2) \\
{[10.46-11.84]}\end{array}$ & $\begin{array}{l}12.41(3.2) \\
{[11.36-13.46]}\end{array}$ & 0.05 \\
\hline SF-36 Physical & $\begin{array}{l}73.29(15.0) \\
{[68.55-78.03]}\end{array}$ & $\begin{array}{l}66.86(18.5) \\
{[60.87-72.84]}\end{array}$ & 0.005 & $\begin{array}{l}89.27(16.1) \\
{[84.20-94.34]}\end{array}$ & $\begin{array}{l}84.93(12.8) \\
{[80.78-89.10]}\end{array}$ & 0.4 \\
\hline SF-36 Role Physical & $\begin{array}{l}45.12(40.0) \\
{[32.37-57.87]}\end{array}$ & $\begin{array}{l}34.61(37.4) \\
{[22.48-46.75]}\end{array}$ & 0.09 & $\begin{array}{l}82.93(34.2) \\
{[72.13-93.72]}\end{array}$ & $\begin{array}{l}69.23(40.3) \\
{[56.15-82.31]}\end{array}$ & 0.05 \\
\hline SF-36 Role Emotional & $\begin{array}{l}64.23(44.3) \\
{[50.23-78.22]}\end{array}$ & $\begin{array}{l}50.43(49.5) \\
{[34.39-66.47]}\end{array}$ & 0.1 & $\begin{array}{l}96.01(13.1) \\
{[91.87-100.0]}\end{array}$ & $\begin{array}{l}76.92(40.6) \\
{[63.77-90.08]}\end{array}$ & 0.006 \\
\hline SF-36 Energy & $\begin{array}{l}63.05(17.5) \\
{[57.51-68.58]}\end{array}$ & $\begin{array}{l}51.15(16.7) \\
{[45.73-56.57]}\end{array}$ & 0.0001 & $\begin{array}{l}82.68(15.7) \\
{[77.71-87.65]}\end{array}$ & $\begin{array}{l}65.70(16.2) \\
{[60.44-71.0]}\end{array}$ & 0.00002 \\
\hline SF-36 Emotional Health & $\begin{array}{l}38.53(16.7) \\
{[33.25-43.82]}\end{array}$ & $\begin{array}{l}37.85(14.5) \\
{[33.15-42.54]}\end{array}$ & ns & $\begin{array}{l}30.34(8.0) \\
{[27.80-32.88]}\end{array}$ & $\begin{array}{l}33.34(12.3) \\
{[29.36-37.32]}\end{array}$ & 0.05 \\
\hline SF-36 Social Function & $\begin{array}{l}61.89(22.9) \\
{[54.67-69.11]}\end{array}$ & $\begin{array}{l}69.87(21.4) \\
{[62.93-76.81]}\end{array}$ & 0.06 & $\begin{array}{l}85.97(15.1) \\
{[81.21-90.74]}\end{array}$ & $\begin{array}{l}75.96(21.3) \\
{[69.04-82.88]}\end{array}$ & 0.01 \\
\hline SF-36 Pain & $\begin{array}{l}44.93(17.9) \\
{[39.30-50.58]}\end{array}$ & $\begin{array}{l}39.17(17.1) \\
{[33.62-44.71]}\end{array}$ & 0.001 & $\begin{array}{l}78.54(21.6) \\
{[71.71-85.36]}\end{array}$ & $\begin{array}{l}65.32(21.2) \\
{[58.44-72.20]}\end{array}$ & 0.004 \\
\hline SF-36 General Health & $\begin{array}{l}61.70(10.4) \\
{[58.42-65.0]}\end{array}$ & $\begin{array}{l}60.64(9.5) \\
{[57.57-63.71]}\end{array}$ & 0.09 & $\begin{array}{l}57.68(7.9) \\
{[55.18-60.18]}\end{array}$ & $\begin{array}{l}59.49(9.6) \\
{[56.38-62.59]}\end{array}$ & ns \\
\hline SF-36 Total & $\begin{array}{l}56.59(15.1) \\
{[51.83-61.36]}\end{array}$ & $\begin{array}{l}51.32(16.2) \\
{[46.07-56.58]}\end{array}$ & 0.005 & $\begin{array}{l}75.43(10.5) \\
{[72.10-78.75]}\end{array}$ & $\begin{array}{l}66.36(14.5) \\
{[61.68-71.05]}\end{array}$ & 0.0008 \\
\hline Mc Gill Sensory & $\begin{array}{l}5.59(4.4) \\
{[4.57-7.33]}\end{array}$ & $\begin{array}{l}7.97(3.9) \\
{[6.69-9.25]}\end{array}$ & 0.009 & $\begin{array}{l}1.78(3.0) \\
{[0.84-2.72]}\end{array}$ & $\begin{array}{l}3.97(4.5) \\
{[2.51-5.44]}\end{array}$ & 0.02 \\
\hline Mc Gill Affective & $\begin{array}{l}1.92(2.1) \\
{[1.26-2.59]}\end{array}$ & $\begin{array}{l}2.23(1.9) \\
{[1.62-2.84]}\end{array}$ & 0.13 & $\begin{array}{l}0.39(1.0) \\
{[0.08-0.70]}\end{array}$ & $\begin{array}{l}0.61(1.1) \\
{[0.25-0.98]}\end{array}$ & 0.2 \\
\hline Mc Gill Total & $\begin{array}{l}7.88(6.1) \\
{[7.88-5.95]}\end{array}$ & $\begin{array}{l}10.20(5.4) \\
{[8.46-11.95]}\end{array}$ & 0.03 & $\begin{array}{l}2.17(3.8) \\
{[0.98-3.36]}\end{array}$ & $\begin{array}{l}4.59(5.1) \\
{[2.95-6.23]}\end{array}$ & 0.01 \\
\hline Linton-Halldén & $\begin{array}{l}75.0(24.9) \\
{[67.14-82.86]}\end{array}$ & $\begin{array}{l}87.77(23.1) \\
{[80.29-95.25]}\end{array}$ & 0.0007 & $\begin{array}{l}42.46(25.8) \\
{[34.30-50.62]}\end{array}$ & $\begin{array}{l}64.33(28.7) \\
{[55.03-73.64]}\end{array}$ & 0.00001 \\
\hline Average pain (VAS) & $\begin{array}{l}38.8(23.8) \\
{[31.3-46.3]}\end{array}$ & $\begin{array}{l}48.6(19.6) \\
{[42.3-55.0]}\end{array}$ & 0.002 & $\begin{array}{l}11.1(17.0) \\
{[5.7-16.5]}\end{array}$ & $\begin{array}{l}20.7(20.3) \\
{[14.1-27.3]}\end{array}$ & 0.01 \\
\hline Number of medications & $\begin{array}{l}0.80(0.8) \\
{[0.53-1.07]}\end{array}$ & $\begin{array}{l}0.49(0.7) \\
{[0.24-0.73]}\end{array}$ & 0.4 & $\begin{array}{l}0.49(0.7) \\
{[0.27-0.70]}\end{array}$ & $\begin{array}{l}0.33(0.6) \\
{[0.13-0.53]}\end{array}$ & 0.9 \\
\hline Side difference, $\mathrm{cm}$ & $\begin{array}{l}0.22(0.4) \\
{[0.09-0.35]}\end{array}$ & $\begin{array}{l}0.58(0.4) \\
{[0.44-0.73]}\end{array}$ & 0.00002 & $\begin{array}{l}0.0(0.0) \\
{[-]}\end{array}$ & $\begin{array}{l}0.25(0.4) \\
{[0.13-0.53]}\end{array}$ & $<0.00001$ \\
\hline Finger-floor distance, $\mathrm{cm}$ & $\begin{array}{l}12.0(13.5 \\
{[7.7-16.2]}\end{array}$ & $\begin{array}{l}15.9(13.6) \\
{[11.5-20.3]}\end{array}$ & 0.02 & $\begin{array}{l}5.4(6.4) \\
{[3.4-7.5]}\end{array}$ & $\begin{array}{l}8.5(8.6) \\
{[5.7-11.2]}\end{array}$ & 0.06 \\
\hline
\end{tabular}

Data indicate unadjusted means (standard deviations) [95\% confidence intervals]; upper part: patient documented outcomes; lower part: clinician-documented outcomes.

nose, and hand, compared with best-practice physiotherapy. Thus, the study had a pragmatic approach, using a strong active control. Since it was the first study of its kind, the design did not stipulate a single primary outcome parameter, but used a set of comparable functional scores and quality of life scores as primary outcomes, as well as clinical parameters documented by a blinded cli- nician as secondary outcomes. Patients suffered from chronic low back pain and had severe problems before the treatment. Both groups improved statistically and clinically significantly in the primary outcomes, as seen by two multivariate analyses of covariance. This was corroborated by the objectively documented clinical measures which were used as secondary outcomes at post- 
Table 8. Results of treatment in secondary outcome variables over time: clinician-rated outcomes

\begin{tabular}{|c|c|c|c|c|c|c|}
\hline \multirow[t]{2}{*}{ Variable } & \multicolumn{2}{|c|}{ After 1st treatment } & \multirow[t]{2}{*}{$p$} & \multicolumn{2}{|c|}{ End of treatment } & \multirow[t]{2}{*}{$p$} \\
\hline & Power Point & physiotherapy & & Power Point & physiotherapy & \\
\hline \multicolumn{7}{|l|}{ Form of the spine } \\
\hline S shape & $31(38.7 \%)$ & $8(10.0 \%)$ & 0.00001 & $26(32.5 \%)$ & $14(17.5 \%)$ & 0.01 \\
\hline Stretched & $5(6.2 \%)$ & $11(13.7 \%)$ & & $13(16.25 \%)$ & $15(18.75 \%)$ & \\
\hline Kyphosis left & $3(3.7 \%)$ & $3(3.7 \%)$ & & $0(0 \%)$ & $3(3.7 \%)$ & \\
\hline Hyperlordosis & $1(1.2 \%)$ & $8(10.0 \%)$ & & $2(2.5 \%)$ & $1(1.2 \%)$ & \\
\hline Kyphosis right & $1(1.2 \%)$ & $9(11.2 \%)$ & & $0(0 \%)$ & $6(7.5 \%)$ & \\
\hline \multicolumn{7}{|l|}{ Height of spina illiaca superior } \\
\hline Equal & $31(38.7 \%)$ & $12(15.0 \%)$ & 0.0003 & $41(51.2 \%)$ & $25(31.2 \%)$ & 0.0001 \\
\hline Left higher & $2(2.5 \%)$ & $7(8.7 \%)$ & & $0(0 \%)$ & $6(7.5 \%)$ & \\
\hline Right higher & $8(10 \%)$ & $20(25 \%)$ & & $0(0 \%)$ & $8(10 \%)$ & \\
\hline \multicolumn{7}{|l|}{ Pain } \\
\hline None & $15(18.7 \%)$ & $9(11.2 \%)$ & 0.1 & $31(38.7 \%)$ & $13(16.2 \%)$ & 0.002 \\
\hline At rest & $5(6.5 \%)$ & $2(2.5 \%)$ & & $4(5 \%)$ & $7(8.7 \%)$ & \\
\hline When moving & $8(10 \%)$ & $5(6.2 \%)$ & & $4(5 \%)$ & $10(12.5 \%)$ & \\
\hline On pressure & - & - & & - & - & \\
\hline Multiple & $13(16.2 \%)$ & $23(28.7 \%)$ & & $2(2.5 \%)$ & $9(11.2 \%)$ & \\
\hline Symphysis painful & $22(27.5 \%)$ & $27(33.7 \%)$ & 0.15 & $3(3.75)$ & $12(15 \%)$ & 0.007 \\
\hline \multicolumn{7}{|l|}{ Medial malleolus symmetry } \\
\hline Symmetric & $21(26.2 \%)$ & $11(13.7 \%)$ & 0.11 & $39(48.7 \%)$ & $22(27.5 \%)$ & 0.0002 \\
\hline Asymm. left & $9(11.2 \%)$ & $13(16.2 \%)$ & & $1(1.2 \%)$ & $7(8.7 \%)$ & \\
\hline Asymm. right & $11(13.7 \%)$ & $15(18.7 \%)$ & & $1(1.2 \%)$ & $10(12.5 \%)$ & \\
\hline Faber test positive & $13(16.2 \%)$ & $26(32.5 \%)$ & 0.002 & $3(3.7 \%)$ & $9(11.2 \%)$ & 0.05 \\
\hline Trendelenburg sign positive & $3(3.7 \%)$ & $0(0 \%)$ & 0.08 & 0 & 0 & $\mathrm{na}^{\mathrm{a}}$ \\
\hline
\end{tabular}

treatment. The experimental treatment, PPT, was significantly better than standard treatment: the level of improvement was generally larger, as testified by significant group differences, and tended to be stronger in the treated group as documented by a significant interaction of the time by group interaction in the SF-36 variables and by significant differences at follow-up in the clinical variables. Thus, the experimental treatment is better than best-practice standard physiotherapy. In order to definitely document a stronger effect of the experimental treatment over standard physiotherapy, a definitive study should be launched with larger numbers and a well-chosen single outcome, most likely the Linton-Halldén Score.

\section{Interpretation of the Results}

When interpreting these findings, we have to consider that the control group was a strong, active control. Physiotherapy treatment is considered gold-standard guideline treatment for chronic low back pain and considered evidence based [29, 33]. It uses mobilization, movement, and relaxation techniques and has to be considered effective. This can be seen in the strong improvement of patients in this group over the time course of the study, although, strictly speaking, a no-treatment control would have to be documented in order to definitively prove this. But we can assume that most chronic patients would not improve to the same degree naturally during 5 or 6 weeks [47]. Against this background, it is interesting to see that, in addition to the significant time trend, all analyses show a stronger improvement with PPT that is significantly different from physiotherapy. For the quality of life scores of the SF36 , this results in a significant interaction term of the multivariate analysis, documenting a differential development of the scores over time. Inspection of the univariate results and the raw scores shows that PPT leads to better outcomes in all variables. This is specifically documented by clinician-rated clinical variables that were assessed by a clinician who was blind to treatment allocation (Table 8). Even variables that are difficult to change, such as the shape of the back, clinical testing signs, and measurable asymmetries show strong change and significant differences at the end of the treatment. 
Thus, the analysis both in its principal component as well as in the confluence of data and trends in the secondary analysis suggests that PPT is more effective than standard physiotherapy.

Is this effect specific for the trigger and reflex points PPT is using? We do not know. This study was not designed as a mechanistic one and hence no control for the activity of the reflex points was installed. Judging from placebo-controlled trials of acupuncture, for instance, it can be assumed that any type of stimulation will produce some effect, and it might be difficult to prove specificity [48]. An individual patient data meta-analysis of acupuncture has shown that these effects are specific, but it took several very large studies to tease this small specific effect apart from the generic effects of treatment and stimulation [49].

However, there are indirect hints as to the specificity of effects: The fact that the clinical testing points towards a rebalancing of side asymmetries seems to suggest that the underlying theory might be in fact correct, which stipulates that pressing distant reflex points regulate pelvic muscles and thus changes asymmetric pressure on vertebral muscles. But from a pragmatic point of view, this question of specificity does not seem to be the most important one. For patients who are chronic sufferers, this treatment gives them something that is invaluable: the option of self-care. This is, because PPT can be applied by patients themselves after a short instruction. Hence, it has to be considered superior to other types of treatments that need more complicated, time-consuming, and expensive procedures. Considering the fact that pharmacological treatments for chronic pain are discouraged by practically all guidelines because of either potential side effects, as with NSAIDs [50], or the potential for dependence with other substances [51, 52], uncomplicated alternatives such as PPT are most welcome. Our data show that PPT is effective and uncomplicated, as we had no dropouts due to adverse events or other complications. It might therefore be a priority for purchasers and insurers to integrate such a simple and inexpensive treatment into their portfolio.

\section{Limitations of the Study}

This was the very first randomized controlled trial of PPT. Therefore, the study has to be considered a pilot. For a pivotal study, a clearly defined primary outcome would have been essential. This was not possible, as no previous experience was able to suggest which outcome would be the best. Also, the study was not blinded for patients. Patients knew that two active treatments would be compared and since it was impossible to blind the new treatment, it is possible that some reporting bias might have occurred. Had this been the case, though, we would have expected that subjective and objective data should di- verge, which is not the case. Thus, reporting bias is an unlikely explanation for our data. Moreover, since both treatments were advertised as active, we doubt that there was a strong effect of any such bias.

The study was designed as a superiority study. The expected superiority was in general proven, as there were both significant time and group effects, and the univariate tests at the end of treatment as well as after the first treatment were generally significant and in favor of the experimental treatment (Table 8). Considering that both groups started at the same baseline levels and that baseline scores were used as predictors, it is interesting to see that even after one treatment there is a group difference that is carrying through to the end. The fact that the interaction term time by group was only significant for the quality of life scores of the SF-36 shows that both treatments improve patients over time and in parallel, but PPT is more effective, as the significant group term shows. In order to definitively demonstrate this, a larger study with a single outcome is necessary. Using the Linton-Halldén score as an example, the effect size of the difference at follow-up was $d=0.47$, and it would require 97 patients per group using this outcome to reach a power goal of $90 \%$ or 73 per group to reach a power goal of $80 \%$. Thus, a pivotal study would likely have to use about 100 patients per group.

Since this was a first study, we did not install a longterm follow-up and hence cannot say anything about the sustainability of effects. This is clearly a drawback and should be remedied in a follow-up study.

\section{Conclusion}

Bearing this caveat in mind we conclude that PPT, a reflexology type of treatment for chronic low back pain, is a good, safe, inexpensive, and widely available alternative to standard forms of treatment, especially because it can be used as a self-care method. Our clinical and patient-reported data show that it is at least as effective as standard physiotherapy, and potentially more effective. Further research is likely to document superior effects more stringently. Therefore, this treatment warrants further study.

\section{Acknowledgement}

We thank Mr. Gerhard Egger for his willingness to let us evaluate his technique and the Foundation of Natural Sciences and Technical Research for supporting this study. 


\section{Statement of Ethics}

The study was approved by the local ethics committee of Carinthia (No.: A05/15) and meets the requirements of ICH-GCP as well as the requirements of the Declaration of Helsinki.

\section{Disclosure Statement}

The authors declare no potential conflicts of interest, no financial relationships with any organizations that might have an interest in the submitted work in the previous years, no other relationships or activities that could appear to have influenced the submitted work. The authors assume responsibility for the overall content and integrity of this article.

\section{Funding Sources}

The study was funded by the Foundation of Natural Sciences and Technical Research in Vaduz, Liechtenstein.

\section{Author Contributions}

Michael Ofner was PI on this study. He wrote the protocol, designed the study, and was responsible for data collection. He also wrote parts of the manuscript. Martin Liebhauser was the trial physician. He included, diagnosed, and tested the patients. Harald Walach analyzed the data and wrote parts of the manuscript.

\section{References}

1 Farioli A, Mattioli S, Quaglieri A, Curti S, Violante FS, Coggon D. Musculoskeletal pain in Europe: the role of personal, occupational, and social risk factors. Scand J Work Environ Health. 2014 Jan;40(1):36-46.

2 Han H, Lee D, Lee S, Jeon C, Kim T. The effects of extracorporeal shock wave therapy on pain, disability, and depression of chronic low back pain patients. J Phys Ther Sci. 2015 Feb; 27(2):397-9.

3 Global Burden of Disease Study 2013 Collaborators: Global, regional, and national incidence, prevalence, and years lived with disability for 301 acute and chronic diseases and injuries in 188 countries, 1990-2013: a systematic analysis for the Global Burden of Disease Study 2013. Lancet. 2015 Aug;386(9995): 743-800.

4 Pellisé F, Balagué F, Rajmil L, Cedraschi C, Aguirre M, Fontecha CG, et al. Prevalence of low back pain and its effect on health-related quality of life in adolescents. Arch Pediatr Adolesc Med. 2009 Jan;163(1):65-71.

5 Rottenberg Y, Jacobs JM, Stessman J. Prevalence of pain with advancing age brief report. J Am Med Dir Assoc. 2015 Mar;16(3):264. e1-5.

6 Mehling WE, Gopisetty V, Acree M, Pressman A, Carey T, Goldberg H, et al. Acute low back pain and primary care: how to define recovery and chronification? Spine. 2011 Dec; 36(26):2316-23.

7 Spijker-Huiges A, Groenhof F, Winters JC, van Wijhe M, Groenier KH, van der Meer K. Radiating low back pain in general practice: incidence, prevalence, diagnosis, and longterm clinical course of illness. Scand J Prim Health Care. 2015 Mar;33(1):27-32.

8 Ekman M, Jönhagen S, Hunsche E, Jönsson L. Burden of illness of chronic low back pain in Sweden: a cross-sectional, retrospective study in primary care setting. Spine. 2005 Aug; 30(15):1777-85.

9 Murray CJ, Vos T, Lozano R, Naghavi M, Flaxman AD, Michaud C, et al. Disability-adjusted life years (DALYs) for 291 diseases and injuries in 21 regions, 1990-2010: a systematic analysis for the Global Burden of Disease Study 2010. Lancet. 2012 Dec;380(9859): 2197-223.
10 Seo JH, Kim JH, Yang KI, Hong SB. Late use of electronic media and its association with sleep, depression, and suicidality among Korean adolescents. Sleep Med. 2017 Jan;29:7680 .

11 Zycha H. Theorie und Erfahrung in der Medizin: Orthodoxe Wissenschaft und ganzheitliche Kybernetik. Forsch Komplementarmed. 1998;5(1 Suppl S1):52-9.

12 Wellington J. Noninvasive and alternative management of chronic low back pain (efficacy and outcomes). Neuromodulation. 2014 Oct;17 Suppl 2:24-30.

13 Capra F, Luisi PL. The Systems View of Life. A Unifying Vision. Cambridge: Cambridge University Press; 2014. https://doi.org/10. 1017/CBO9780511895555.

14 Finckh I. Fußreflexzonentherapie. In: Walach H, Michael S, Schlett S, editors. Das große Komplementärhandbuch für Ärzte und Apotheker. Stuttgart: Wissenschaftliche Verlagsgesellschaft; 2018. pp. 316-25.

15 Finckh I. Medizinische Reflexzonentherapie am Fuss. Freiburg: Karger; 2016.

16 Yip YB, Tse SH. The effectiveness of relaxation acupoint stimulation and acupressure with aromatic lavender essential oil for nonspecific low back pain in Hong Kong: a randomised controlled trial. Complement Ther Med. 2004 Mar;12(1):28-37.

17 Hsieh LL, Kuo CH, Lee LH, Yen AM, Chien KL, Chen TH: Treatment of low back pain by acupressure and physical therapy: randomised controlled trial. BMJ. 2006 Mar 25; 332(7543):696-700.

18 Sinharay R, Gong J, Barratt B, Ohman-Strickland P, Ernst S, Kelly FJ, et al. Respiratory and cardiovascular responses to walking down a traffic-polluted road compared with walking in a traffic-free area in participants aged 60 years and older with chronic lung or heart disease and age-matched healthy controls: a randomised, crossover study. Lancet. 2018 Jan; 391(10118):339-49.

19 Allemani C, Matsuda T, Di Carlo V, Harewood R, Matz M, Nikšić M, et al. Global surveillance of trends in cancer survival 2000-14 (CONCORD-3): analysis of individual records for 37513025 patients diagnosed with one of 18 cancers from 322 population-based registries in 71 countries. Lancet. 2018 Mar 17;391(10125):1023-1075.

20 Critchley DJ, Ratcliffe J, Noonan S, Jones RH, Hurley MV. Effectiveness and cost-effectiveness of three types of physiotherapy used to reduce chronic low back pain disability: a pragmatic randomized trial with economic evaluation. Spine. 2007 Jun;32(14):1474-81.

21 Ebenbichler GR, Inschlag S, Pflüger V, Stemberger R, Wiesinger G, Novak K, et al. Twelveyear follow-up of a randomized controlled trial of comprehensive physiotherapy following disc herniation operation. Clin Rehabil. 2015 Jun;29(6):548-60.

22 Karagülle M, Karagülle MZ. Effectiveness of balneotherapy and spa therapy for the treatment of chronic low back pain: a review on latest evidence. Clin Rheumatol. 2015 Feb; 34(2):207-14

23 Smeets RJ. Do lumbar stabilising exercises reduce pain and disability in patients with recurrent low back pain? Aust J Physiother. 2009;55(2):138.

24 Yogitha B, Nagarathna R, John E, Nagendra H. Complimentary effect of yogic sound resonance relaxation technique in patients with common neck pain. Int J Yoga. 2010 Jan;3(1): 18-25.

25 Cecchi F, Negrini S, Pasquini G, Paperini A, Conti AA, Chiti M, et al. Predictors of functional outcome in patients with chronic low back pain undergoing back school, individual physiotherapy or spinal manipulation. Eur J Phys Rehabil Med. 2012 Sep;48(3):371-8.

26 Rubinstein SM, van Middelkoop M, Assendelft WJ, de Boer MR, van Tulder MW. Spinal manipulative therapy for chronic low-back pain: an update of a Cochrane review. Spine. 2011 Jun;36(13):E825-46.

27 Rubinstein SM, van Middelkoop M, Assendelft WJ, de Boer MR, van Tulder MW. Spinal manipulative therapy for chronic low-back pain. Cochrane Database Syst Rev. 2011 Feb;CD008112(2):CD008112.

28 Kuijpers T, van Middelkoop M, Rubinstein SM, Ostelo R, Verhagen A, Koes BW, et al. A systematic review on the effectiveness of pharmacological interventions for chronic non-specific low-back pain. Eur Spine J. 2011 Jan;20(1):40-50. 
29 van Middelkoop M, Rubinstein SM, Kuijpers T, Verhagen AP, Ostelo R, Koes BW, et al. A systematic review on the effectiveness of physical and rehabilitation interventions for chronic non-specific low back pain. Eur Spine J. 2011 Jan;20(1):19-39.

30 Savigny P, Kuntze S, Watson P, Underwood M, Ritchie G, Cotterell M, et al. Low Back Pain: early management of persistent nonspecific low back pain. London: National Collaborating Centre for Primary Care and Royal College of General Practitioners; 2009.

31 Chou R, Deyo R, Friedly J, Skelly A, Hashimoto R, Weimer M, et al. Nonpharmacologic therapies for low back pain: A systematic review for an american college of physicians clinical practice guideline. Ann Intern Med. 2017 Apr;166(7):493-505.

32 Qaseem A, Wilt TJ, McLean RM, Forciea MA; Clinical Guidelines Committee of the American College of Physicians. Noninvasive treatments for acute, subacute, and chronic low back pain: A clinical practice guideline from the American College of Physicians. Ann Intern Med. 2017 Apr;166(7):514-30.

33 Steffens D, Maher CG, Pereira LS, Stevens ML, Oliveira VC, Chapple M, et al. Prevention of low back pain: A systematic review and meta-analysis. JAMA Intern Med. 2016 Feb; 176(2):199-208.

34 Wancura-Kampik I. Segmentanatomie - Der Schlüssel zu Akupunktur, Neuralterapie und Manualtherapie. München: Urban \& Fischer; 2009.

35 Friedrich M, Likar R. Evidenz- und konsensusbasierte österreichische Leitlinien für das Management akuter und chronischer unspezifischer Kreuzschmerzen. Wien Klin Wochenschr. 2007;119(5-6):189-97.
36 Wiesinger GF, Nuhr M, Quittan M, Ebenbichler G, Wölfl G, Fialka-Moser V. Cross-cultural adaptation of the Roland-Morris questionnaire for German-speaking patients with low back pain. Spine. 1999 Jun;24(11):1099103

37 Gaul C, Mette E, Schmidt T, Grond S. Praxistauglichkeit einer deutschen Version des "Oswestry Low Back Pain Disability Questionnaire”. Ein Fragebogen zur Beeinträchtigung durch Rückenschmerzen. Schmerz. 2008 Feb;22(1):51-8.

38 Bullinger M, Kirchberger I. Der SF-36 Fragebogen zum Gesundheitszustand (SF-36). Handbuch für die deutschsprachige Fragebogenversion. Göttingen: Hogrefe; 1998.

39 Kiss I, Müller H, Abel M. The McGill Pain Questionnaire-german version. A study on cancer pain. Pain. 1987 May;29(2):195-207.

40 Linton SJ, Halldén K. Can we screen for problematic back pain? A screening questionnaire for predicting outcome in acute and subacute back pain. Clin J Pain. 1998;14(3):209-15.

41 Schmidt CO, Lindena G, Pfingsten M, Kohlmann T, Chenot JF. Vergleich zweier Screening-Fragebogen für Patienten mit Rückenschmerzen. Erfassung von Risikofaktoren für eine Chronifizierung. Schmerz. 2014 Aug; 28(4):365-73.

42 Levangie PK. Four clinical tests of sacroiliac joint dysfunction: the association of test results with innominate torsion among patients with and without low back pain. Phys Ther. 1999 Nov;79(11):1043-57.

43 Bagwell JJ, Bauer L, Gradoz M, Grindstaff TL. The reliability of Faber test hip range of motion measurements. Int J Sports Phys Ther. 2016 Dec;11(7):1101-5.

44 Rawlins M. What constitutes credible evidence? London: Office of Health Economics; 2013.
45 Committee for Proprietary Medicinal Products (CPMP). Points to consider on switching between superiority and non-inferiority in Products E-EAftEoM (ed). London: EMA; 2000, CPMP/EWP/482/99.

46 Moher D, Hopewell S, Schulz KF, Montori V, Gøtzsche PC, Devereaux PJ, et al. CONSORT 2010 explanation and elaboration: updated guidelines for reporting parallel group randomised trials. BMJ. 2010 Mar;340:c869.

47 Hasanpour-Dehkordi A, Dehghani A, Solati K. A comparison of the effects of Pilates and McKenzie Training on pain and general health in men with chronic low back pain: A randomized trial. Indian J Palliat Care. 2017 Jan-Mar;23(1):36-40.

48 Haake M, Müller HH, Schade-Brittinger C, Basler HD, Schäfer H, Maier C, et al. German Acupuncture Trials (GERAC) for chronic low back pain: randomized, multicenter, blinded, parallel-group trial with 3 groups. Arch Intern Med. 2007 Sep;167(17):1892-8.

49 Vickers AJ, Cronin AM, Maschino AC, Lewith G, MacPherson H, Foster NE, et al.; Acupuncture Trialists' Collaboration. Acupuncture for chronic pain: individual patient data meta-analysis. Arch Intern Med. 2012 Oct;172(19):1444-53.

50 Gor AP, Saksena M. Adverse drug reactions of nonsteroidal anti-inflammatory drugs in orthopedic patients. J Pharmacol Pharmacother. 2011 Jan;2(1):26-9.

51 Dowell D, Haegerich TM, Chou R: CDC guideline for prescribing opioids for chronic pain - United States 2016. JAMA. 2016 Apr; 315(15):1624-45.

52 Gøtzsche PC. Deadly Psychiatry and Organised Denial. Copenhagen: People's Press; 2015 . 